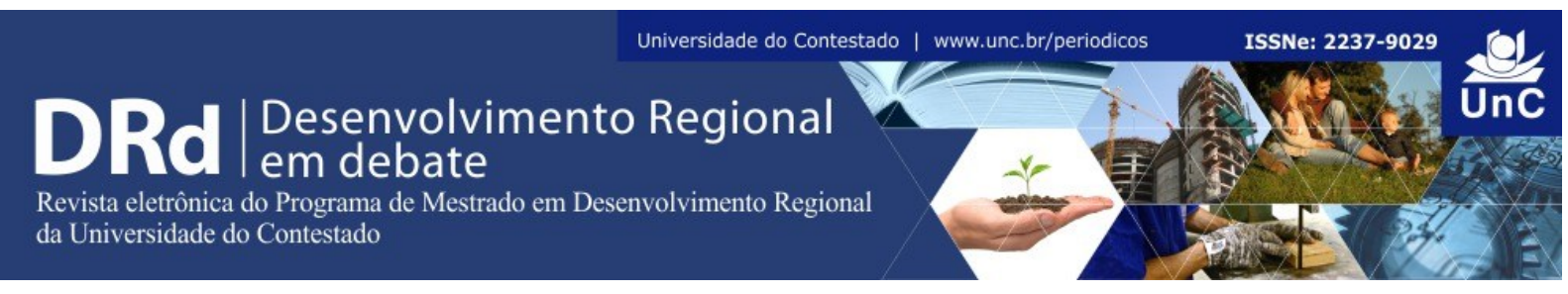

\title{
ERVA-MATE E NEUROPROTEÇÃO: INOVAÇÃO E DESENVOLVIMENTO TERRITORIAL NO PLANALTO NORTE CATARINENSE COM BASE EM ESTUDOS PRÉ-CLÍNICOS
}

\author{
Simone Molz ${ }^{1}$ \\ Fabiana Kalyne Ludka ${ }^{2}$
}

\begin{abstract}
RESUMO
Levando em conta a necessidade de se converter o grande arsenal químico da biodiversidade brasileira em potencial econômico, considerações devem ser feitas em relação ao entendimento do processo de inovação em fitoterápicos e sua contribuição para o desenvolvimento de uma região. Erva-mate (Illex paraguariensis) é uma espécie nativa do Planalto Norte Catarinense, utilizada tradicionalmente pela população devido aos seus efeitos estimulantes para o sistema nervoso. A morte neuronal (neurodegeneração) está envolvida em diversas doenças neurológicas e por isso a busca por substâncias neuroprotetoras a partir de plantas medicinais pode ser considerada uma estratégia de inovação e desenvolvimento. $\mathrm{O}$ objetivo deste artigo é fazer uma revisão da literatura, na busca de evidências que dão subsídios para uma possível indicação terapêutica da erva-mate levando em consideração os seus efeitos neuroprotetores. A metodologia de estudo utilizou pesquisa bibliográfica em base de dados indexados (Pubmed). Foram encontradas 14 publicações sobre os efeitos da ervamate no sistema nervoso central entre os anos de 2000 e 2016, sendo que a metade deles (7) foi realizada nos últimos 4 anos. Conclui-se que os dados presentes na literatura e do nosso próprio grupo de pesquisa dão subsídios para o uso tradicional da erva-mate e contribuem para a busca de um medicamento fitoterápico a partir desta planta. Entretanto, esta perspectiva envolve um longo caminho a ser percorrido, que depende de uma articulação interdisciplinar entre a academia e a indústria, além de investimento em pesquisa e inovação.
\end{abstract}

Palavras-chave: Produtos naturais. Fitoterápico. Erva-mate. Neuroproteção. Planalto Norte Catarinense.

\footnotetext{
${ }^{1}$ Graduada em Farmácia, com doutorado em Neurociência pela Universidade Federal de Santa Catarina (UFSC) e Universidad Autónoma de Madrid. Atualmente é professora do Curso de Farmácia da Universidade do Contestado. Santa Catarina. Brasil. E-mail: simonem@unc.br

${ }^{2}$ Graduada em Farmácia, com doutorado em Bioquímica pela UFSC. Atualmente é professora do Curso de Farmácia da Universidade do Contestado. Santa Catarina. Brasil. E-mail: fabianak@unc.br
} 


\section{ABSTRACT \\ YERBA MATE AND NEUROPROTECTION: INNOVATION AND TERRITORIAL DEVELOPMENT OF NORTH PLATEAU CATARINENSE BASED ON PRE- CLINICAL STUDIES}

Considering the need to convert Brazillian chemical arsenal and biodiversity into economic potential, some considerations should be done about innovation in the phytotherapic drugs system and how it can contribute to the development of a region. Yerba mate (Illex paraguariensis) is a native specie from North Plateau Catarinense that has been traditionally used due to its central nervous system stimulant proprieties. Neuronal death (neurodegeneration) is involved in many neurological diseases, therefore the search for neuroprotective substances from medicinal plants can be considered an innovation strategy to territorial development. The purpose of this article is to review the literature searching for evidence for a possible yerba mate neuroprotective therapeutic indication. We have found 14 publications with yerba mate effects on the central nervous system, conducted among 20002016. Half of them (7) were done in the last 4 years. The results presented here provide a basis for the development of a herbal medicine from yerba mate. However, this approach depends on interdisciplinary link between academia and industry, as well as investment in research and innovation.

Keywords: Natural products. Phytomedicine. Yerba mete. Neuroprotection. North Plateau Catarinense.

\section{INTRODUÇÃO}

A utilização de plantas medicinais como recurso terapêutico é especialmente importante para países em desenvolvimento. A fitoterapia é uma alternativa viável tanto em relação aos custos como pelo aproveitamento de espécies vegetais nativas, em especial quando a região detém uma importante biodiversidade, como é o caso do Brasil, com a floresta Amazônica, o cerrado e a Mata Atlântica (VIEGAS; BOLZANI, 2009).

A busca por alívio e cura de doenças pela ingestão de plantas talvez tenha sido uma das primeiras formas de utilização dos produtos naturais. A história do desenvolvimento das civilizações Oriental e Ocidental é rica em exemplos da utilização de recursos naturais na medicina. No caso do Brasil, a sua história está intimamente ligada ao comércio de produtos naturais (as especiarias) e o pau-Brasil (Cesalpinia echinata) (VIEGAS; BOLZANI; BARREIRO, 2006).

O profundo conhecimento do arsenal químico da natureza, pelos povos primitivos e pelos indígenas pode ser considerado fator fundamental para descobrimento de substâncias com potencial para o desenvolvimento de medicamentos ao longo do tempo. A convivência e o aprendizado com os mais diferentes grupos étnicos trouxeram valiosas contribuições para o desenvolvimento da pesquisa em produtos naturais, do conhecimento da relação íntima entre a estrutura química de um determinado composto e suas propriedades biológicas (ALBUQUERQUE; HANZANI, 2006). 
A etnofarmacologia é uma ciência multidisciplinar que estuda a diversidade cultural e biológica. Especificamente trata dos usos que comunidades tradicionais fazem das espécies vegetais para fins terapêuticos. Ela utiliza recursos das ciências humanas e biológicas para traduzir e representar o saber popular/tradicional em conhecimento científico. A pesquisa etnofarmacológica envolve, em suas diversas etapas, diferentes áreas do conhecimento, uma vez que está ligada à Antropologia, ao se relacionar com várias comunidades e culturas, à Botânica e à Farmacologia. Dessa forma, o conhecimento das comunidades contribui para os estudos científicos e vice-versa. Essa ação conjunta pode ser um valioso caminho de identificação das plantas úteis à produção de medicamentos (ELIZABETSKI, 2003).

A abordagem etnodirigida para a descoberta de novos medicamentos a partir de produtos naturais consiste na seleção de espécies de acordo com a indicação de grupos populacionais específicos em determinados contextos de uso, enfatizando a busca pelo conhecimento construído localmente a respeito de seus recursos naturais e a aplicação que fazem deles em seus sistemas (ALBUQUERQUE; HANZANI, 2006). A seleção de plantas para pesquisa e desenvolvimento de fitoterápicos baseada em relatos de um determinado efeito terapêutico em humanos e em animais tem grande importância na descoberta de fármacos, já que seu uso tradicional pode ser considerado como uma pré-triagem quanto à utilidade terapêutica (RODRIGUES; CARLINI, 2002).

No que se refere às plantas medicinais nativas do Planalto Norte Catarinense, há séculos a erva-mate vem sendo utilizada na forma de chimarrão ou chá devido a seus efeitos estimulantes para o sistema nervoso central. Além disso, o conhecimento etnofarmacológico sugere a utilização da erva-mate como auxiliar no tratamento de transtornos do humor como a depressão. A depressão é um transtorno psiquiátrico que no Brasil apresenta prevalência de 18,4 \%, uma das mais altas do mundo (BROMET et al., 2011). É uma doença caracterizada por permanente tristeza, sentimento de culpa e pensamentos de suicídio ou morte (NESTLER et al., 2002) que limitam a vida social do paciente e acarretam altos custos financeiros (PRINCE et al., 2007). Logo, é muito promissor do ponto de vista de inovação e desenvolvimento, que estudos sejam conduzidos com extratos desta importante planta do Planalto Norte Catarinense no sentido de comprovar estes dados etnofarmacológicos e através de uma articulação multidisciplinar com outros setores envolvidos na cadeia da erva-mate, trazer estes conhecimentos à luz da inovação e desenvolvimento territorial.

Guilhermino, Quental e Bontempo (2012) propõem e analisam um sistema de inovação em fitomedicamento. Para estes autores os principais agentes envolvidos compreendem a indústria, as Instituições de Pesquisa e desenvolvimento (PID) e o Estado estes últimos representados pelas ações do governo federal compreendidas na elaboração de políticas e regulamentação.

O medicamento fitoterápico, de acordo com a legislação sanitária brasileira, é o medicamento obtido exclusivamente a partir de matérias-primas ativas vegetais, sendo caracterizado pelo conhecimento da eficácia e dos riscos de seu uso, assim com a reprodutibilidade e a constância da sua qualidade, tanto da matéria-prima vegetal quanto do produto tecnologicamente acabado (BRASIL, 2004).

Muitos são os desafios enfrentados para que uma planta medicinal adquira grau de medicamento fitoterápico. Resumidamente, pode-se citar: (i) muitos dos insumos farmacêuticos vegetais utilizados por indústrias brasileiras não são fornecidos a partir de 
plantas cultivadas, sendo obtidas principalmente por extrativismo e, não raro, tendo origem em material importado. $\mathrm{O}$ extrativismo produz mais problemas do que soluções para o setor. Apresenta vegetais com grande heterogeneidade de constituintes, adulterações por equívocos na correta identificação da espécie botânica e, não menos grave, representa ameaça de extinção de espécies por colheitas indiscriminadas; (ii) necessidade de grande investimento em pesquisa e desenvolvimento; (iii) desarticulação entre o setor privado e o setor público; (iv) gestão dos programas estabelecidos para operacionalizar as políticas públicas, regulação e fomento (ALVES, 2013).

Segundo Dallabrida et al. (2014), a região do Planalto Norte Catarinense possui potencial para criação de uma identidade territorial sustentável a partir da cultura da ervamate. De acordo com Azevedo (2003) a emergência do desenvolvimento local, é uma afirmação da identidade e valorização das características próprias de cada território, que passa a ser um agente ativo capaz de estimular seu próprio desenvolvimento. Considerando que o Planalto Norte Catarinense se destaca em área com cultivo de erva-mate (IBGE, 2015), estudos que visem estruturar e ampliar toda a cadeia produtiva da erva-mate, desde a sua produção até a comercialização final, numa tentativa de agregar valor á matéria prima, desempenham um importante papel no desenvolvimento econômico da região em questão.

A estrutura do presente artigo compreende, inicialmente, uma fundamentação teórica, contemplando informações sobre a importância histórica dos produtos naturais. Merece destaque também a contextualização e análise de um sistema de inovação em fitomedicamento e a sua importância para o desenvolvimento territorial. Na continuidade, após referir-se aos procedimentos metodológicos, se faz uma descrição dos principais efeitos neuroprotetores da erva-mate, com ênfase nos resultados obtidos através das pesquisas realizadas com o extrato hidroalcoólico de erva-mate conduzidos na Universidade do Contestado. Nas considerações finais, são feitos alguns indicativos sobre as possibilidades e os desafios para que a erva-mate possa vir a transformar-se um medicamento fitoterápico e dessa forma contribuir no desenvolvimento econômico sustentável do território do Planalto Norte Catarinense.

\section{PROPRIEDADES MEDICINAIS DA ERVA-MATE: UMA ESTRATÉGIA PARA O DESENVOLVIMENTO DO PLANALTO NORTE CATARINENSE}

Inicialmente, será feita uma contextualização do leitor sobre a importância histórica dos produtos naturais no desenvolvimento de medicamentos. Também serão abordadas as questões regulatórias referentes ao desenvolvimento de fitoterápicos no Brasil bem como a contextualização e análise de um sistema de inovação em fitomedicamento e a sua importância para o desenvolvimento territorial.

\section{IMPORTÂNCIA HISTÓRICA DOS PRODUTOS NATURAIS}

A história do desenvolvimento das civilizações Oriental e Ocidental é rica em exemplos da utilização de recursos naturais na medicina. O profundo conhecimento do arsenal químico da natureza, pelos povos primitivos e pelos indígenas pode ser considerado fator fundamental para descobrimento de substâncias com potencial para o desenvolvimento de 
medicamentos ao longo do tempo. A natureza forneceu muitos modelos moleculares que fundamentaram estudos e inspiraram o desenvolvimento da síntese orgânica clássica e existem vários exemplos que podem ilustrar esse assunto. Os curares eram drogas obtidas de diversas espécies de Strychnos e Chondodendron utilizadas pelos índios para produzir flechas envenenadas para caça e pesca. Somente no século XIX Boehm isolou o principal constituinte ativo do curare, a tubocurarina (VIEGAS; BOLZANI, 2009).

Outro exemplo marcante que causou grande impacto na humanidade foi a descoberta das substâncias alucinógenas, largamente utilizadas pelos antigos em suas práticas religiosas. O ópio, preparado dos bulbos de Papaver somniferum, era utilizada desde a época dos Sumérios (4000 a.C.), havendo relatos na mitologia grega atribuindo à papoula do ópio o simbolismo de Morfeu, o deus do sono. Em 1803, Derosne iniciou os primeiros estudos sobre a constituição química do ópio e em 1804, na França, Armand Séquin isolou o seu constituinte majoritário, a morfina. A grande eficácia da morfina como analgésico foi reconhecida após a invenção da seringa hipodérmica (1853), e foi largamente utilizada pelas tropas dos Estados Unidos durante a Guerra de Secessão (1861-1865). Nos dias de hoje, a morfina ainda é um dos principais analgésicos opioides utilizados em grande escala no tratamento das dores crônicas e dores causadas pelo câncer (YUAN et al. 2016).

Durante a colonização espanhola do Peru, em 1630, os jesuítas observaram que a os índios utilizavam as cascas secas de espécies de Cinchona para tratamento de alguns tipos de febre e em 1820, foi isolado a quinina, que durante quase trezentos anos foi o único princípio ativo eficaz contra a malária. Dada a importância das plantas para a medicina da época, a Química e a Medicina passaram a ter uma estreita relação. Talvez o marco mais importante para o desenvolvimento dos fármacos a partir de produtos naturais de plantas tenha sido o descobrimento dos salicilatos obtidos a partir das cascas de salgueiro (Salix alba). Vários outros cientistas empenharam-se em melhorar os rendimentos e a qualidade dos salicilatos naturais até que, em 1898, descobriu-se o ácido acetil-salicílico (AAS). A partir de 1897 os laboratórios da Bayer lançaram o medicamento a partir do AAS sob o nome de Aspirina ${ }^{\circledR}$ e anda hoje, o AAS continua sendo alvo de inúmeras pesquisas sobre sua aplicação terapêutica como analgésico e anti-inflamatório e na inibição da agregação plaquetária (LUENGO, 2005).

Com relação às drogas anticancer aprovadas entre 1940-2002, aproximadamente 54\% são derivadas de produtos naturais ou tem suas estruturas químicas inspiradas no conhecimento relacionado aos produtos naturais. Durante o período compreendido entre 1981 e 2002, a aplicação de produtos naturais no desenvolvimento de novas drogas obteve bastante sucesso. Nos próximos anos, drogas derivadas de produtos naturais cresceram significativamente, especialmente em relação à classe dos anti-hipertensivos, em que cerca de $64 \%$ dos novos medicamentos tem sua origem a partir de produtos naturais (NEWNAMM al., 2003).

Dessa foram, o emprego das plantas medicinais na recuperação da saúde tem evoluído o longo dos tempos. No decorrer dos séculos, produtos de origem vegetal constituíram as bases para o tratamento de diferentes doenças e o ser humano percebeu, de alguma forma, a presença nas plantas de algo que, administrado sob a forma de mistura complexa (o extrato) ou como substância pura (isolada), tem a propriedade de provocar reações benéficas capazes de resultar na recuperação da saúde (YUAN et al., 2016). 


\section{ERVA-MATE: INOVAÇÃO EM FITOMEDICAMENTO E DESENVOLVIMENTO TERRITORIAL DO PLANALTO NORTE CATARINENSE}

Ilex paraguariensis é uma árvore de até $20 \mathrm{~m}$ de altura, dotada de copa densa e muito ramificada. As folhas são de cor verde escura, simples, alternadas, ablongas ou abovadas, curto pecioladas, de 6-20 cm de comprimento. No Sul do Brasil, no Uruguai, Argentina e Paraguai é consumida sob a forma de chimarrão, uma bebida típica, muito amarga, ingerida quente e sem adoçante. No restante do país é usado na forma de chá, ou como bebida refrescante gelada (BRACESCO et al., 2011).

Bracesco et al (2011) e Heck e Mejia (2007) em suas revisões sobre a erva-mate concluíram que a composição química das folhas da espécie erva-mate é muito complexa. A diversidade da composição química da erva-mate pode estar relacionada com alguns aspectos evolutivos de desenvolvimento da planta, à época da colheita, características do solo e do clima (VALDUGA et al, 1997), às etapas do processamento industrial (ERMELINDRO et al., 2002) e técnicas de extração utilizadas (GNOATTO et al, 2007).

Vários compostos químicos foram identificados na erva-mate, como metilxantinas, taninos e compostos fenólicos (FILIP et al, 2001), saponinas (GOSMANN et al,1995) e componentes minerais, entre outros (VALDUGA et al, 1997). Ao pesquisarem sete espécies do gênero Ilex na América do Sul, Filip et al (2001) determinaram que a espécie llex paraguariensis seja a que apresenta maior teor de derivados do ácido cafeico. As folhas de erva-mate do estado de Santa Catarina apresentam teores significativamente superiores em ácido gálico e cafeína do que as do estado do Rio Grande do Sul (STREIT et al, 2007). Embora já existam muitos produtos no mercado utilizando partes da planta ou extratos de erva-mate, nenhum até o momento adquiriu grau de fitoterápico. Tendo em vista os efeitos benéficos dos compostos fitoquímicos presentes na erva-mate, estudos pré-clínicos que utilizem extratos desta planta com o objetivo de validar a sua utilização terapêutica podem ser considerados uma estratégia de inovação para o território do Planalto Norte Catarinenses.

Inovação é o conjunto total das principais atividades para inserção de algo novo, resultado do fortalecimento da defensável vantagem competitiva de uma empresa. A inovação é um dos fatores fundamentais do sucesso, sendo elemento essencial na conquista de vantagem competitiva. Ainda, a inovação, em sua essência, é um processo que envolve a geração e execução de ideias, as quais levam à criação e aplicação de conhecimento. A inovação também é considerada elemento fundamental para a evolução econômica e social dos povos e tem disso estudada em seus aspectos (BARBIERI et al., 2010).

Guilhermino; Quental e Bontempo (2012) propõem e analisam um sistema de inovação em fitomedicamento (SIF). Estes autores apresentam uma visão organizada sobre os principais agentes envolvidos, que compreendem a indústria, as Instituições de Pesquisa e desenvolvimento (PID) e o Estado - estes últimos representados pelas ações do governo federal compreendidas na elaboração de políticas e regulamentação. A conformação esquemática do SIF envolve um conjunto de atividades produtivas, que vai da extração e/ou produção de plantas medicinais passando pelo conjunto de atividades produtivas que as utilizam como matéria-prima (alimentos, cosméticos e medicamentos) e chegam até o mercado (público ou provado). Este sistema também inclui agentes que se relacionam direta ou indiretamente com o setor produtivo, tais como Universidades e Institutos de Pesquisa. Embora o meio ambiente não seja um agente direto do sistema, é pertinente observar a sua 
relevância no SIF; um sistema no qual a biodiversidade alimentam as organizações de formas distintas. Logo, o meio ambiente deve afetar, e ser afetado pelos agentes do SIF.

Quando se considera a cadeia tecnológica e produtiva de derivados de plantas medicinais, observa-se que este apresenta cinco segmentos (Figura 1).

Figura 1 - Cadeia tecnológica e produtiva de derivados de plantas medicinais

\section{Indústria (Tecnologias ) ou segmento Produto para o mercado}

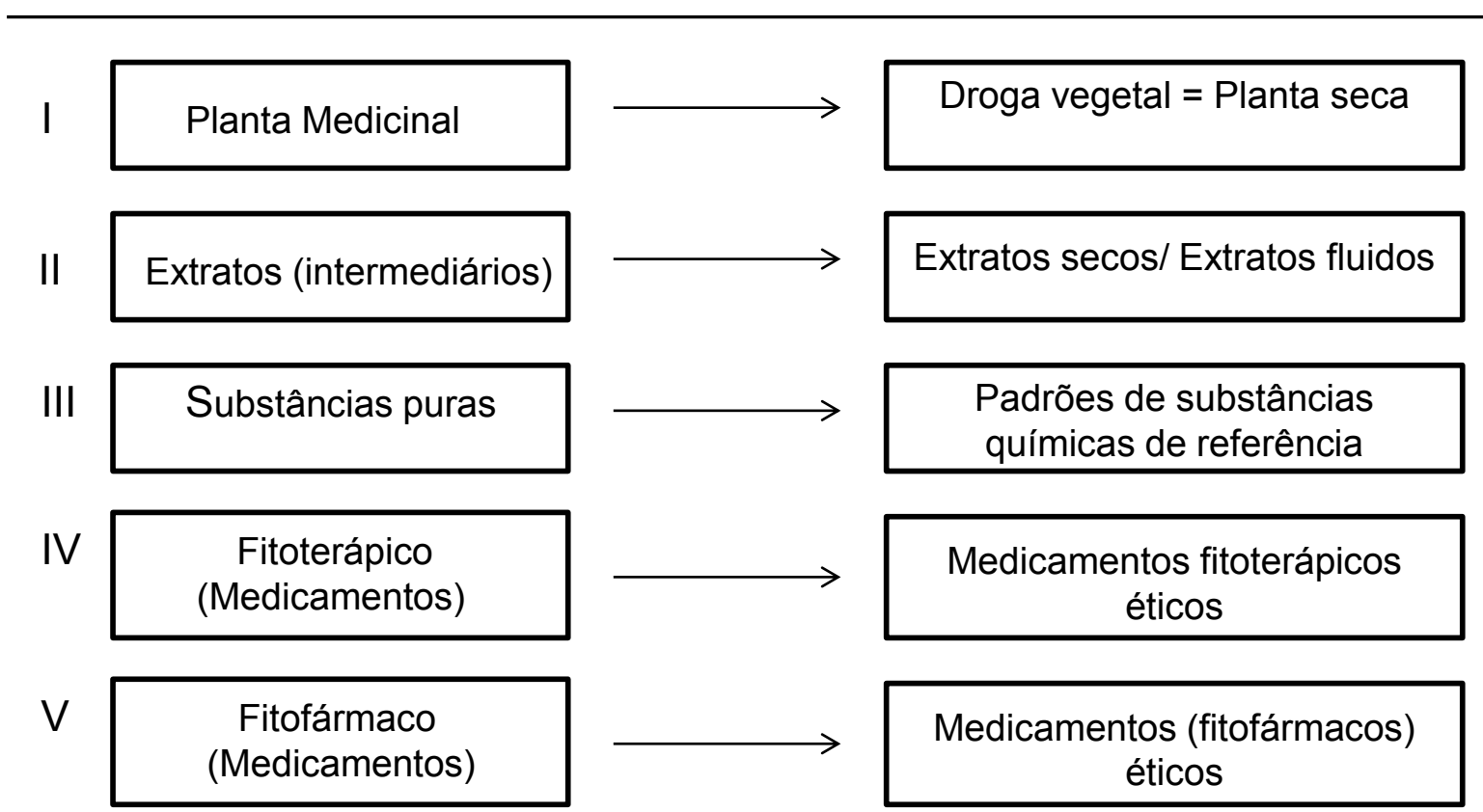

Fonte: Adaptado de Guilhermino, Quental e Bontempo (2012)

Pelas análises da figura 1 pode-se constatar que com o avanço da cadeia tecnológica (industrial) ocorre concomitantemente com a maior agregação de valor do produto resultante das etapas. Cada segmento responde por parâmetros éticos e atende às regulamentações específicas que rege sua atividade ou produção, de forma que diferentes níveis de produtos deverão, em geral, atender às exigências de diferentes órgãos regulatórios (BRASIL, 2004).

O segmento produtivo I compreende os fornecedores e a matéria prima vegetal (cultivo de plantas medicinais), que no Brasil ainda ocorre através do processo extrativista. $\mathrm{O}$ custo da produção de plantas medicinais é considerado alto, sendo determinado pela espécie vegetal e pelo sistema de cultivo. O retorno ocorre em médio e longo prazo, dependendo do tamanho da área cultivada e do capital investido. Segundo Correa Jr, Graça e Sheffer 2004, observa-se um crescimento sistemático das áreas cultivadas com plantas medicinais, em resposta às demandas do mercado. Ainda quando se considera este segmento, alguns desafios podem ser apontados, como por exemplo, o aperfeiçoamento das técnicas de produção e beneficiamento, com atenção especial ao uso de tecnologias mais adequadas para secagem e na obtenção de concentração desejável dos princípios ativos.

Os segmentos produtivos II e III são considerados intermediários. O segmento produtivo II compreende a obtenção de extratos, que podem ser utilizados diretamente por profissionais da saúde como um recurso terapêutico (extratos fluidos, tinturas), ou podem ser 
utilizados como matéria prima, a partir da incorporação de um adjuvante estabilizador, para a produção de fitomedicamentos. Alguns parâmetros chaves no processamento de extratos devem ser considerados, como, por exemplo, parte da planta a ser utilizada, coleta do material vegetal, método de extração e processos de purificação, tipo e concentração do solvente, razão entre o material vegetal bruto e o solvente. Estes parâmetros devem ser considerados para se evitar diferenças nas concentrações dos princípios ativos e dessa forma se obter padronização do extrato bruto. $\mathrm{O}$ produto desta etapa tecnológica pode ser utilizado pela indústria farmacêutica.

O segmento III compreende os processos tecnológicos de purificação e separação dos princípios ativos das plantas medicinais, podendo utilizar como matéria prima a droga vegetal ou o produto do segmento II (extrato bruto). Um exemplo de investimento neste segmento ocorreu pela empresa Merk, que investiu em plantações próprias de jaborandi e de fava d'anta no Maranhão, para a extração de pilocarpina e rutina, respectivamente, que constituem produtos farmoquímicos para exportação (GUILHERMINO; QUENTAL; BONTEMPO, 2012).

Os segmentos IV e V compreendem processos de transformação farmacêutica. No Brasil, existem basicamente dois tipos de empresas que atuam neste segmento. De um lado estão as grandes empresas, cujo maior parte do faturamento (cerca de 90\%) se deve a comercialização de produtos sintéticos com apenas uma pequena parcela dedicada à venda de medicamentos de origem vegetal, composta principalmente de princípios ativos isolados da matriz vegetal (fitofármacos). De outro lado, estão os laboratórios menores, com produção principalmente de fitoterápicos.

As normas e critérios para a produção, comercialização e registro de fitoterápicos no Brasil ainda é um entrave para as pequenas indústrias, já que o registro sanitário apresenta uma importante barreira, em função dos custos relacionados à validação científica destes produtos. Os padrões legais para registro de fitoterápicos exigem segurança de uso, eficácia na utilização e qualidade dos processos e do produto (BRASIL, 2004). Limitações técnicas e financeiras aliada aos desafios de inovação tecnológica necessária para o desenvolvimento de fitoterápicos fazem com que as empresas não tenham fôlego para investir nesta área. Levando em consideração estas constatações, deve ser isto que atrasa o desenvolvimento de um fitoterápico a partir da erva-mate e por isso a mesma continua no segmento I do SIF, sendo explorada apenas como matéria prima pela indústria de alimentos e cosméticos.

Dallabrida et al. (2011 apud 2014, p. 47) registrou que:

O território é uma construção social resultante de relações de poder que, simultaneamente, contém a dimensão da unidade, da solidariedade e da conflitualidade. Trata-se de relações inseridas na história de uma sociedade situada territorialmente. Refere-se a uma fração do espaço, historicamente construída pelas interelações dos atores sociais, econômicos e institucionais que atuam neste recorte espacial, apropriada a partir de relações de poder sustentadas em motivações políticas, sociais, econômicas, culturais ou religiosas, oriundas do Estado, de grupos sociais ou corporativos, instituições ou indivíduos.

Para Dallabrida et al. (2014), o que convencionamos teoricamente chamar de território, não se trata de qualquer recorte espacial, sendo, portanto, diferente do que chamamos de região. Sendo assim, estes atores defendem que a região do Planalto Norte Catarinense possui potencial para criação de uma identidade territorial sustentável a partir da

DRd - Desenvolvimento Regional em debate (ISSNe 2237-9029) 
cultura da erva-mate. Por outro lado, os autores também apontam alguns desafios como: (1) pressão de empresas para controlar a produção de erva-mate, inclusive com a compra de ervateiras por multinacionais; (2) desconhecimento local dos potenciais da cadeia produtiva da erva-mate; (3) desconexão dos grupos de investigação e falta de estudos sobre as potencialidades da conversão das áreas de remanescentes da Mata Atlântica em espaços de multifuncionalidades, com padrões de exploração sustentáveis e (4) uma excessiva visão agrarista no padrão de desenvolvimento regional, além da baixa participação cidadã no processo de debate sobre desenvolvimento regional.

No caminho para inovar e agregar mais tecnologia em produtos derivados da ervamate, estudos devem ser conduzidos para organizar toda a cadeia produtiva de maneira multidisciplinar. Inicia-se pelas questões relacionadas ao cultivo da planta, que deve ser estudada em termos de se evidenciar as melhores condições de cultivo e consequentemente padronizar o processo de obtenção da matéria prima (segmento I). Apesar de inicial, este segmento apresenta grande importância, pois pode agregar valor à matéria prima e consequentemente apresenta uma alternativa para melhorar a renda dos produtores da região do Planalto Norte Catarinense. A partir da matéria prima padronizada, parte-se para a padronização do extrato seco (segmentos II e II), numa tentativa de se obter a concentrações constantes dos constituintes fitoquímicos e então partir para a extração de constituintes principais ou utilização de fitocomplexos para os estudos pré-clínicos. Neste momento, vale a pena salientar a importância destes estudos pré-clínicos, em que se estudam então os efeitos biológicos dos extratos padronizados, geralmente em modelos animais de estudo, com o intuito de se avaliar a eficácia e segurança. Os resultados obtidos a partir destes estudos podem (ou não) impulsionar os segmentos IV e V, com a participação efetiva da indústria e a consolidação de um medicamento fitoterápico.

Devido à falta de investimentos em pesquisa e desenvolvimento, existem poucos fitoterápicos totalmente desenvolvidos e registrados no país a partir de espécies nativas. Atualmente, o Brasil ainda é considerado um país com baixo nível de competitividade na cadeia produtiva de plantas medicinais e fitoterápicos e ainda continua sendo um tradicional importador de todos os segmentos dessa cadeia (RODRIGUES; NOGUEIRA e PARREIRA, 2008). No que tange a temática da erva-mate, além da sua utilização na forma de chimarrão, existem vários produtos destinados ao uso externo (principalmente cosméticos) e alimentícios (chás, farinha enriquecida com erva-mate, bebidas destiladas contendo extrato de erva-mate) e que certamente impulsionam a cadeia produtiva da erva-mate. Entretanto, aqui vale salientar que nenhum deles utiliza matéria prima padronizada (seja na forma de planta seca ou extratos) ou apresentaram estudos suficientes para que se tenha uma indicação terapêutica para a utilização da erva-mate, e dessa forma ainda se permanece estagnado nos segmentos I ou II do SIF.

Além dos desafios apontados anteriormente, outras limitações também devem ser transpostas para que o desenvolvimento de fitoprodutos se transforme em estratégia para o desenvolvimento econômico de uma região. Isto se deve principalmente ao fato de que muitos dos insumos farmacêuticos vegetais utilizados por indústrias brasileiras não são fornecidos a partir de plantas cultivadas, sendo obtidas principalmente por extrativismo. O extrativismo produz mais problemas do que soluções para o setor, pois apresenta vegetais com grande heterogeneidade de constituintes, adulterações por equívocos na correta identificação da espécie botânica e, não menos grave, representa ameaça de extinção de espécies por colheitas indiscriminadas. Neste sentido, o conhecimento do uso tradicional de plantas medicinais e a 
busca de sustentabilidade no novo cenário da economia solidária, pretende-se afirmar nesta reflexão a potencial contribuição de plantas medicinais e fitoterápicas para o desenvolvimento socioeconômico do território do Planalto Norte Catarinense. Isto significa dizer que é não apenas viável, mas necessário, identificar oportunidades de agregação de valor através da organização e desenvolvimento de cadeias produtivas orientadas para o mercado, aqui entendido como um conjunto de demandas em saúde.

Voltando à questão regulatória pertinente aos fitoterápicos, deve-se levar em conta a Agência Nacional de Vigilância Sanitária (ANVISA), a qual regulamenta que medicamentos fitoterápicos devem ser testados e receber concessão de registro pela Anvisa para serem lançados no mercado. Antes disso, necessitam também de comprovação de eficácia e segurança realizada por meio de estudos pré-clínicos e clínicos (BRASIL, 2004). Dessa maneira, as fases de estudo para medicamentos fitoterápicos são praticamente as mesmas de um medicamento sintético, mas diferem na aprovação do Conselho de Gestão do Patrimônio Genético (CGEN), que é exclusivo das pesquisas com plantas. Por outro lado, a pesquisa com plantas medicinais apresenta algumas vantagens, uma vez que a natureza já "sintetizou" os princípios ativos que constituem o denominado complexo fitoterápico. Em consequência, a pesquisa básica pode ser bastante reduzida e encurtada. Outra vantagem é que os métodos de validação são mais simples e menos rigorosos do que o de uma molécula sintética nova. Testes de farmacocinética e biodisponibilidade não são exigidos devido à natureza do fitocomplexo.

Assim como ocorre para os medicamentos sintéticos, os fitoterápicos são submetidos a testes de toxicologia aguda, subaguda e crônica em roedores e não roedores, bem como alguns estudos especiais in vitro. Posteriormente, se a toxicologia animal e in vitro autorizar, devem ser realizados os estudos clínicos de fases I, II e III, nos quais serão avaliados diversos parâmetros para testar a segurança e tolerabilidade do produto (medicamento fitoterápico).

\section{DOENÇAS DO SISTEMA NERVOSO CENTRAL E NEUROPROTEÇÃO}

As doenças neurodegenerativas são condições debilitantes que resultam da degeneração progressiva e/ou morte das células responsáveis pelo sistema nervoso - os neurônios. São problemas médicos extremamente complexos e limitados pelo tratamento farmacológico pouco efetivo podendo afetar pessoas de todas as idades. $\mathrm{O}$ aumento da expectativa de vida da população vem aumentando a incidência de doenças neurodegenerativas, que se tornam ainda mais graves com o passar dos anos. Uma das doenças neurodegenerativas mais frequentes no mundo é a depressão, com prevalência de $17 \%$ na população ao longo da vida (NESTLER et al., 2002).

Segundo a Organização Mundial de Saúde (OMS), 450 milhões de indivíduos tem problemas mentais e psicossociais (BORDIN, 2006). Um recente trabalho realizado com a população brasileira acima de 18 anos demonstrou que a prevalência de depressão no Brasil é de 4,1,\%, o que corresponde à aproximadamente 5,5 milhões de pessoas afetadas por essa doença. Além disso, a depressão foi mais prevalente em indivíduos com 40-59 anos ou acima de 80 anos, em mulheres (duas vezes maior do que em homens) e em indivíduos morando na área urbana e em pessoas com menor nível educacional (SILVA et al., 2014). Além disso, estima-se que 50 a $60 \%$ dos pacientes com depressão, não se recuperam totalmente com a 
utilização de medicamentos para este fim (TRIVEDI et al., 2006). Isso se deve ao fato de que os antidepressivos disponíveis hoje na prática clínica, apresentam demora de semanas para que o paciente perceba uma melhora da sintomatologia clínica (RACAGNI; POPOLI, 2008) o que por muitas vezes leva a não adesão do tratamento. Além disso, os efeitos indesejáveis causados pela utilização de antidepressivos - boca seca, aumento ou diminuição do peso, cefaleia - contribuem para dificultar o uso desses fármacos.

Já é conhecido que na depressão, ocorre uma disfunção das principais células responsáveis pelo processamento da informação cerebral, os neurônios. Os neurônios passam por alterações em sua forma (morfologia), alterações bioquímicas que então se refletem na perda da viabilidade destas células, resultando em última instância na perda de função e aparecimento dos sintomas da doença (SANACORA et al., 2008). A avaliação destes mecanismos ainda é muito difícil de realizar em humanos, necessitando-se assim a utilização de modelos animais de estudo, que são úteis não somente para o estudo da patofisiologia das doenças, mas também servem como uma forma de se avaliar a resposta ao tratamento com fármacos ou novas moléculas com atividade terapêutica. Os modelos animais de estudo serão discutidos com mais detalhes mais adiante nos materiais e métodos.

Dentre as possíveis causas de morte celular dos neurônios (neurodegeneração), podese apontar a hipótese glutamatérgica. O glutamato é um dos 20 aminoácidos essenciais e no sistema nervoso central é um neurotransmissor muito importante para o desempenho de diversas funções cerebrais normais. Embora o glutamato seja essencial às funções neuronais normais, o excesso de glutamato nos neurônios é prejudicial e está associado a diversas doenças neurodegenerativas como a doença de Parkinson, doença de Alzheimer, além da isquemia cerebral e doenças psiquiátricas como a depressão (SANACORA et al., 2008). Tendo em vista essa característica fisiopatológica, alguns modelos de estudo utilizam o altas concentrações ou doses de glutamato para induzir neurodegeneração em modelos animais e possibilitar o estudo de novas estratégias terapêuticas.

Já foi demonstrado que o consumo de metilxantinas presentes no café, especificamente a cafeína, está inversamente correlacionado com sintomas de depressão (LUCAS et al., 2011; DOOD et al., 2015) e que as metilxantinas também apresentam diversos efeitos protetores para as células neuronais (ZHAO et al., 2010; BOISON et al., 2011). Os dados citados anteriormente e evidências de que as folhas de erva-mate do estado de Santa Catarina apresentam teores significativamente superiores em cafeína do que as do estado do Rio Grande do Sul (STREIT et al, 2007), encorajam os estudos fitoquímicos e biológicos a partir de extratos de erva-mate proveniente do Planalto Norte Catarinense, com o intuito de inovação na área de desenvolvimento de medicamentos fitoterápicos neuroprotetores com base nesta planta.

\section{PROCEDIMENTOS METODOLÓGICOS}

Os dados do presente trabalho foram coletados usando a literatura do portal eletrônico PubMed, utilizando como descritores: "Illex paraguariensis", "yerba mate", "neuroprotection", "brain" e "behaviour". A pesquisa bibliográfica foi realizada entre os dias 01/07/2016 e 13/07/2016 e foram encontrados 14 artigos publicados no período entre 20002016. Os trabalhos incluídos nesta revisão foram publicados em revistas indexadas, 
reconhecidas internacionalmente e que apresentavam ensaios farmacológicos pré-clínicos in vitro e in vivo com extratos de Illex paraguariensis. Só foram incluídos estudos nos quais a identidade da planta foi cuidadosamente verificada e que se referiam a Illex paraguariensis.

\section{EFEITOS DE EXTRATOS DE ERVA-MATE SOB O SISTEMA NERVOSO CENTRAL}

Os artigos consultados demonstraram que a utilização de extratos de erva-mate possui efeitos significativos sob o sistema nervoso central, uma vez que já foram descritos efeitos tipo-ansiolítico (SANTOS et al., 2015), tipo-antidepressivo (REIS et al., 2014; LUDKA et al., 2016), estimulante (HECK; MEJIA, 2007), anticonvulsivante (BRANCO et al., 2013) e analgésico em modelo de dor neuropática pós-operatória (LIM et al., 2015). A utilização de extrato de erva-mate também aumenta as defesas antioxidante em regiões encefálicas (CITTADINI et al., 2015) e altera a secreção da enzima peroxidase (FILLIP et al., 2000).

Em relação às ações centrais do extrato de erva-mate que estão correlacionadas com a obesidade, já foi descrito que reduz a hiperfagia e a resistência à leptina no hipotálamo (LIMA et al., 2014), aumenta a saciedade (HUSSEIN et al., 2011) e também diminui a neuroinflamação em modelos animais de obesidade (PIMENTEL et al., 2013) .

Tendo em vista o conhecimento popular de que a erva-mate apresenta efeito estimulante para o sistema nervoso central, dois estudos demonstraram que a administração do extrato de erva-mate melhora a memória em roedores (COLPO et al., 2007; PREDIGER et al., 2008). No estudo de Prediguer et al (2008), o efeito do extrato de erva-mate se deu parcialmente devido ao antagonismo de receptores de adenosina. Ainda, um estudo realizado por Milioli et al (2007) relatou que a utilização do extrato de erva-mate melhorou os sintomas motores e cognitivos através da atuação em receptores adenosinérgicos em um modelo de doença de Parkinson em camundongos. Em conjunto, estes estudos suportam parcialmente o uso tradicional da erva-mate como estimulante da cognição através da atuação de metilxantinas em receptores de adenosina.

Dentro deste contexto, um estudo conduzido pelo nosso grupo de pesquisa na Universidade do Contestado demonstrou que a administração de extrato hidroalcoólico de erva-mate desencadeia efeito tipo-antidepressivo em animais experimentais. A quantificação de metilxantinas demonstrou a presença de cafeína e teobromina no extrato hidroalcoólico de erva-mate utilizado. Testes subsequentes demonstraram que o teor de metilxantinas presentes no extrato estudado, desencadeou efeito tipo-antidepressivo comparável ao efeito obtido pela administração do extrato. Tal fato permite inferir que o efeito tipo-antidepressivo desencadeado pelo extrato pode ser atribuído à presença de metilxantinas (LUDKA et al., 2016).

Experimentos adicionais indicaram ainda que o efeito tipo-antidepressivo desencadeado pela administração de extrato hidroalcoólico de erva-mate depende da modulação do sistema glutamatérgico (LUDKA et al., 2016). De forma semelhante, um dos mais promissores antidepressivos incluídos nos últimos anos na prática clínica - a cetamina modula o sistema glutamatérgico para desencadear seu efeito farmacológico (DUMAN, AGHAJANIAN, 2012). 
De forma complementar aos dados citados anteriormente, a administração do extrato hidroalcoólico de erva-mate foi capaz de proteger o hipocampo e o córtex - duas estruturas encefálicas relacionadas a patofisiologia da depressão - dos animais experimentais. Esse efeito dito neuroprotetor foi alcançado através da realização de um ensaio que consistiu em tratar os animais experimentais com o extrato de erva-mate e após tempo adequado retirar as estruturas encefálicas citadas, desafiá-las com glutamato e posteriormente medir a sua viabilidade. Ensaio semelhante, realizado através da administração de metilxantinas (na mesma concentração presente no extrato de erva-mate) aos animais experimentais, resultou em proteção do hipocampo e córtex frontal desafiados com glutamato (LUDKA et al., 2016).

Desta forma, os experimentos comportamentais e bioquímicos demonstram que o extrato de erva-mate desencadeia efeito tipo-antidepressivo e neuroprotetor semelhante ao desencadeado pela administração de metilxantinas, estabelecendo uma intrínseca relação entre os efeitos citados e a presença de metilxantinas no extrato. A Tabela 1 apresenta um resumo dos principais achados do nosso grupo em relação à análise fotoquímica e os efeitos biológicos do extrato de erva-mate.

Tabela 1 - Caracterização fotoquímica e efeitos biológicos demonstrados para o extrato hidroalcoólico de ervamate realizados na Universidade do Contestado

Caracterização Fitoquímica

Metodologia utilizada

Quantificação de metilxantinas (cafeína e teobromina) CLAE $^{1}$ Efeito Biológicos Metodologia utilizada

\begin{tabular}{ll}
\hline Efeito tipo-antidepressivo & Modelo animal preditivo - TSC $^{2}$ \\
\hline Efeito neuroprotetor & Viabilidade celular frente ao desafio por glutamato \\
\hline Modulação do sistema serotonérgico & $\begin{array}{l}\text { Modelo animal preditivo }- \text { TSC e estratégias } \\
\text { farmacológicas }\end{array}$ \\
\hline Modulação do sistema glutamatérgico &
\end{tabular}

Fonte: Dados da Pesquisa (2016)

Vale a pena salientar que o resultado apresentado pelo nosso grupo vai ao encontro do resultado apontado por Reis et al., que demonstraram em 2014, que a administração de uma bebida a base de erva-mate, preparada de forma a mimetizar o chimarrão, apresentou também efeito tipo-antidepressivo nos animais experimentais testados. Estes mesmos autores, verificaram que este efeito do extrato não envolve a inibição da enzima monoamina oxidase e, portanto, não envolve a participação do sistema monoaminérgico. Em conjunto, estes dois estudos se complementam e dão um direcionamento para a participação do sistema glutamatérgico no efeito tipo-antidepressivo e neuroprotetor da erva-mate.

Também é importante enfatizar que dos 14 estudos encontrados na literatura que correlacionam os efeitos da erva-mate no sistema nervoso central, metade deles foram realizados nos últimos quatro anos, evidenciando que este é um tema atual, que atrai o interesse da comunidade científica de vários países. Estas evidências dão suporte para a continuidade destes estudos, especialmente no território do Planalto Norte Catarinense, uma região que produz a matéria prima em larga escala e cuja população utiliza tradicionalmente esta planta devido aos seus efeitos estimulantes. 


\section{CONSIDERAÇÕES FINAIS}

Os dados aqui apresentados confirmam as indicações etnofarmacológicas para a utilização da erva-mate como estimulante do sistema nervoso central e apontam esta planta como promissora do ponto de vista da inovação em fitoterápicos a partir de plantas nativas do Planalto Norte Catarinense, o que poderá contribuir sobremaneira para o desenvolvimento da região. Entretanto, do ponto de vista farmacológico, para que isso ocorra, é imprescindível a avaliação da atividade de extratos de erva-mate em diversos modelos, bem como avaliação toxicológica.

Entretanto, para concluir, não se pode deixar de mencionar que qualquer profissional ou instituição que deseja trabalhar com plantas medicinais esbarra na dificuldade em produzilas ou adquiri-las com confiabilidade na identificação botânica ou mesmo em obter informações sobre em quais condições a espécie foi cultivada. Sendo assim, a área agrotecnológica pode auxiliar as pesquisa na busca por um fitoterápico a partir da erva-mate, visando a disseminação da espécie e sua sustentabilidade e aliando a produção com a otimização do teor do(s) princípio(s) ativo(s), possibilitando a adequação da espécie às condições climáticas locais. Além disto, deve auxiliar em programas de melhoramento genético, produção em ambientes controlados, processamento pós-colheita (secagem e armazenamento). Neste sentido, colaborações estão sendo realizadas entre o nosso grupo de pesquisa e outros grupos de pesquisa da região do Planalto Norte Catarinense com experiência nos temas abordados neste artigo, na procura da troca de informações e conhecimentos que alavanquem ainda mais as pesquisas com erva-mate. O delineamento destes estudos permitirá o fechamento do ciclo multidisciplinar no estudo com plantas medicinais e proporcionará subsídios técnicos para o desenvolvimento de um produto fitoterápico a partir desta planta.

\section{REFERÊNCIAS}

ALBUQUERQUE, U. P.; HANAZAKI, N. As pesquisas etnodirigidas na descoberta de novos fármacos de interesse médico e farmacêutico: fragilidades e perspectiva. Revista Bras.

Farmacognosia, v. 16, Supl. p. 678-689, 2006.

ALVES, L. F. Produção de Fitoterápicos no Brasil: História, Problemas e Perspectivas. Rev. Virtual Quim., v.5, n. 3, p. 450-513, 2013.

AZEVEDO, B. Clusters: os distritos industriais dos países em desenvolvimento. In:

Desenvolvimento em questão. Ijui: Ed Unijui, 2003. p. 99-121.

BARBIERI, J. C. et al. INOVAÇÃO E SUSTENTABILIDADE: NOVOS MODELOS E PROPOSIÇÕES. Revista de Administração de Empresas, v. 50, n. 2, p. 146-154, 2010.

BOISON, D. Methylxanthines, seizures and excitotoxicity. Handb Exp Pharmacol.,v, 200, p. 251-266, 2011.

BORDIN, C. F. W. Atenção farmacêutica na ansiedade e depressão. Aula ministrada para o curso de pós-graduação e Farmacologia, Aplicada na Atenção Farmacêutica. Curitiba. 2006. 
BRACESCO, N. et al. Recent advances on Ilex paraguariensis research: Minireview. J. Ethnopharmacol., v. 136, p. 378- 384, 2011.

BRANCO, C. S. et al. Anticonvulsant, neuroprotective and behavioral effects of organic and conventional yerba mate (Ilex paraguariensis St. Hil.) on pentylenetetrazol-induced seizures in Wistar rats. Brain Res Bull. v.92, p. 60-68, 2013.

BRASIL. Resolução da Diretoria Colegiada n. 48 de 16 de março de 2004. Dispõe sobre o registro de medicamentos fitoterápicos. Diário Oficial da República Federativa do Brasil, Brasília, DF, 16 mar. 2004.

BROMET, E. et al. Cross-national epidemiology of DSM-IV major depressive episode. BMC Med., v. 26; p. 9:90, 2011.

CITTADINI, M. C. et al. Effects of oral phytoextract intake on phenolic concentration and redox homeostasis in murine encephalic regions. Nutr Neurosci, v. 18, p. 316-322. 2015.

COLPO, G. et al. Illex paraguariensis has antioxidant potential and attenuates haloperidolinduced orofacial dyskinesia and memory dysfunction in rats. Neurotox Res, v. 12, n. 3, p. 171-80, 2007.

CORREA JUNIOR, C.; GRAÇA, L. R.; SCHEFFER, M. C. Complexo agroindustrial das plantas medicinais, aromáticas e condimentos no estado do Paraná: diagnóstico e perspectivas, Colombo: Embrapa Florestas, 2004.

DALLABRIDA, V. R. et al. Indicação geográfica da erva-mate no território do contestado: reflexões e projeções. Desenvolvimento Regional em debate, v. 4, n. 2, p. 44-77, 2014.

DODD, F. L. et al. A double-blind, placebo-controlled study evaluating the effects of caffeine and L-theanine both alone and in combination on cerebral blood flow, cognition and mood.

Psychopharmacol., (Berl), v. 232, n. 14, p. 2563-76, 2015.

DUMAN, R. S.; AGHAJANIAN, G. K. Synaptic dysfunction in depression: potential therapeutic targets. Science, v. 5, n. 338 (6103), p. 68-72, 2012.

ELIZABETSKI, E. Etnofarmacologia. Cienc. Cult., São Paulo, v. 55, n. 3, 2003.

ERMELINDRO, M. C. et al. Caracterização físico-química da erva-mate: influências das etapas de processamento industrial. Ciência e Tecnologia de Alimentos, Campinas, v. 22, n.2, p.193-204, 2002.

FILIP, R. et al. Phenolic compounds in seven South American Ilex species. Fitoterapia. v. 72, n. 7, p. 774-778, 2001.

GNOATTO, S.C.B. et al. Influência do método de extração dos teores de metilxantinas em erva-mate (Ilex paraguariensis A. St. Hil., Aquifoliaciae). Química Nova, v. 30, 304-307, 2007.

GOSMANN, G. et al. Triterpenoids saponins from I. paraguariensis. J. Nat. Prod., v. 58, p. 438-441, 1995. 
GUILHERMINO, J. F.; QUENTAL, C.; BONTEMPO, J.V. Phytomedicines Innovation System: Management Challenges for the Development of Phytomedicines from the Brazilian Biodiversity Revista Fitos, v. 7, n 03, 2012.

HECK, C.I.; MEJIA, E. G. Yerba Mate Tea (Ilex paraguariensis): a comprehensive review on chemistry, health implications, and technological considerations. J. Food Sci., v. 72, n. 9, p. 138-51, 2007.

HUSSEIN, G. M. et al. Mate tea (Ilex paraguariensis) promotes satiety and body weight lowering in mice: involvement of glucagon-like peptide-1. Biol Pharm Bull. V. 34(12), p.1849-1855.

INSTITUTO BRASILEIRO DE GEOGRAFIA E ESTATÍSTICA - IBGE. Produção Agrícola Municipal. Disponível em: $<\mathrm{http}: /$ www.sidra.ibge.gov.br/bda/ tabela/listabl.asp? $\mathrm{c}=106 \& \mathrm{z}=\mathrm{p} \& \mathrm{o}=28>$. Acesso em 15 de junho de 2016.

LIM, D. W. et al. Analgesic Effect of Ilex paraguariensis Extract on Postoperative and Neuropathic Pain in Rats. Biol Pharm Bull, v. 38, p. 1573-1579, 2015.

LIMA, M. E.; COLPO, A. C.; SALGUEIRO, W.G.; SARDINHA, G. E.; AVILA, D. S.; FOLMER, V. Ilex paraguariensis Extract Increases Lifespan and Protects Against the Toxic Effects Caused by Paraquat in Caenorhabditis elegans. Int J Environ Res Public Health. v. 26, p. 10091-100104, 2014.

LUCAS, M. et al. Coffee, Caffeine, and Risk of Depression Among Women. Arch Intern Med., v. 26, n. 171(17), p. 1571-1578, 2011.

LUDKA, F. K. et al. Ilex paraguariensis hydroalcoholic extract exerts antidepressant-like and neuroprotective effects: involvement of the NMDA receptor and the L-arginine-NO pathway. Behav Pharmacol., v. 27, n. 4, p. 384-92, 2016.

LUENGO, Marcos B. Uma revisão histórica dos principais acontecimentos da imunologia e da farmacologia na busca do entendimento das doenças inflamatórias. Revista Eletrônica de Farmácia, v. 2, n. 2, p. 64-72, 2005.

MILIOLI, E. M. et al. Effect of acute administration of hydroalcohol extract of Ilex paraguariensis St Hilaire (Aquifoliaceae) in animal models of Parkinson's disease. Phytother Res. v. 21, n. 8, p. 771-6, 2007.

NESTLER, E. J. Preclinical models: status of basic research in depression. Biol Psychiatry, v. 15, n 2(6), p.503-28, 2002.

NEWMAN, D. J.; CRAAG, G. M.; SNADER, K. M. Natural Products as Sources of New Drugs over the Period 1981-2002. J. Nat. Prod., n. 66, p. 1022-1037, 2003.

PRINCE, M. No health without mental health. Lancet, v. 8, n. 370 (9590), p. 859-77, 2007.

PIMENTEL, G. D. et al Yerba mate extract (Ilex paraguariensis) attenuates both central and peripheral inflammatory effects of diet-induced obesity in rats. J Nutr Biochem. v. 24, p.8098818, 2013. 
PREDIGER, R. D. S. et al. Effects of acute administration of the hydroalcoholic extract of mate tea leaves (Ilex paraguariensis) in animal models of learning and memory. $\mathbf{J}$.

Ethnopharmacol. v. 120, p.465-473, 2008.

RACAGNI, G.; POPOLI, M. Cellular and molecular mechanisms in the long-term action of antidepressants. Dialogues Clin Neurosci., v. 10, n. 4, p. 385-400, 2008.

REIS, E.M. et 1. Antidepressant-Like Effect of Ilex paraguariensis in Rats. BioMed Res. Int., p. 1-9, 2014.

RODRIGUES, E.; CARLINI, E. L. Araújo. A importância dos levantamentos etnofarmacológicos no desenvolvimento de fitomedicamentos. Revista Racine, São Paulo, n.70, p.30-35, 2002.

RODRIGUES, W.; NOGUEIRA, J. M.; PARREIRA, L. A. Competitividade da cadeia produtiva de plantas medicinais no brasil: uma perspectiva a partir do comércio exterior. XLVI Congresso da Sociedade Brasileira de Economia, Administração e Sociologia Rural, Anais..., Rio Branco, Brasil. de Economia, Administração e Sociologia Rural, Rio Branco, Brasil, 2008.

SANACORA, G.; RECCANI, G; POPOLI, M. Towards a glutamate hypothesis of depression: an emerging frontier of neuropsychopharmacology for mood disorders.

Neuropharmacol., v.62, p.63-77, 2012.

SANTIN, D.; BENEDETTI, E. L.; REISSMANN, C. B. Nutrição e recomendação de adubação e calcário para a cultura da erva-mate. In: WENDLING, I.; SANTIN, D.

Propagação e nutrição de erva-mate. Brasília, DF: Embrapa, 2015, p. 99-195.

SANTOS, E. C. et al. Anxiolytic-like, stimulant and neuroprotective effects of Ilex paraguariensis extracts in mice. Neuroscience. v. 292, p.13-21, 2015.

SILVA, M. T. et al. Prevalence of depression morbidity among Brazilian adults: a systematic review and meta-analysis. Rev Bras Psiquiatr., n. 36, v. 3, p. 262-70, 2014.

STREIT, N. M. et al. Relation among taste-related compounds (phenolics and caffeine) and sensory profile of erva-mate (Ilex paraguariensis). Food Chem., v. 102, p. 560-564, 2007.

TRIVEDI, M. H. et al. Use of treatment algorithms for depression. Prim Care Companion J Clin Psychiatry, v. 8, n. 5, p. 291-8, 2006.

VALDUGA, E. Caracterização química e anatômica da folha de Ilex paraguariensis Saint Hilaire e de algumas espécies utilizadas na adulteração do mate. Curitiba, Dissertação (Mestrado em Engenharia Florestal) - Setor de Ciências Agrárias, Universidade Federal do Paraná, 1997.

VIEGAS JUNIOR, C.; BOLZANI, V. S.; BARREIRO, E. J. Os produtos naturais e a química medicinal moderna. Quím. Nova, São Paulo, v. 29, n.2, p. 326-337, 2006.

YUAN, H. The Traditional Medicine and Modern Medicine from Natural Products Molecules, v. 21, p. 559-565, 2016. 
ZHAO, X. Caffeinol at the receptor level; Anti-ischemic effect of NMDA receptor blockade is potentiated by caffeine. Stroke, v. 41, n. 2, p. 363-7, 2010.

Artigo recebido em: 22/06/2016

Artigo aprovado em: 16/07/2016 